\title{
Non Linear optical properties of silver nanoparticles doped polyvinyl alcohol
}

Received :21/ 6 / 2018

Accepted : 2 / 9 /2018

\author{
Dr.R. Sh. Alnayli ${ }^{1}$, Hanan Alkazaali ${ }^{1}$ \\ University of Al-Qadisiyah, Department of physics, IRAQ \\ Raad.Anayli@qu.edu.iq, hananalkazaali@gmail.com
}

\begin{abstract}
:
In the present work, synthesis silver nanoparticle by laser ablation by using (Q switched Nd:YAG) pulse duration( $E=80 \mathrm{~mJ}, \lambda=532 \mathrm{~nm})$ of silver metal target in ethanol,Z-scan technique was used to study the nonlinear optical properties, represented by the nonlinear refractive index and nonlinear absorption coefficients of Ag NPs/PVA.In this technique, used CW diode laser $(\lambda=650 \mathrm{~nm}, \mathrm{p}=50 \mathrm{mw})$. The results show that the nonlinear refractive indexnegative (self-defocusing) and nonlinear absorption coefficients two photonabsorption (TPA).
\end{abstract}

KEYWORDS:silver nanoparticle,Polyvinyl Alcohol, Z-scan, nonlinear refractive index, nonlinear absorption coefficients.

\section{1- INTRODUCTION}

Nonlinear optical materials are required in a wide range of important applications, such as optical limiting, optical computing, and optical communication[1].Metal nanoparticles and nanocomposites have, in recent years, received significant attention owing to their unique nonlinear optical (NLO) properties, such as two-photon absorption (TPA), saturable absorption (SA), reverse saturable absorption (RSA), and self-focusing/defocusing arising from nonlinear 
refraction[2,3].The Z-scan method, was applied for the first time more than ten years ago, This method is based on the investigation of changes in Gaussian beam intensity profile in the far field during the moving of the sample through the focal plane $[4,5]$.The surface plasma resonance (SPR), which results from collective electronic excitation at the interface between metal nanoparticles and dielectric matrix, not only is responsible for the linear optical properties but also governs nonlinear optical phenomena [6].Studies of doping transition metal halides into Polyvinyl Alcohol (PVA) are important for determining and controlling the operational characteristic of the differentPVA composites [7]

In this paper we prepared the Ag NPs by laser ablation in a liquid medium used ethanol and doped PVA, then by the technique Z-scan to study the nonlinear optical properties of the nonlinear refractive index and the nonlinear absorption coefficient.

\section{2-EXPERIMENTAL}

2-1 MATERIALS AND METHODS
In this case laser ablation of Ag plate has been done using of $\mathrm{Nd}-\mathrm{YAG}$ pulsed laser $(532 \mathrm{~nm})$ with energy value $(80 \mathrm{~mJ})$ in ethanol and pulses(100,200,300), pulse width 10ns and $6 \mathrm{~Hz}$ repetition rate.PVA films were prepared by dissolving $0.5 \mathrm{~g}$ of PVA powder in $10 \mathrm{ml}$ of DDDW at $50^{\circ}$.themixture was stirred for two hours continuously to form viscous solution. After completing desolation, $8 \mathrm{~mL}$ of silver nanoparticles suspension was added to the $20 \mathrm{~mL}$ aqueous PVA solution, and finally samples were left to dry on a plane surface for one week at room temperature, then use Z-scan experimental, the excitation source was a continuous wave $(\mathrm{CW})$ of $650 \mathrm{~nm}$ diode laser with a beam power of 50 mw for Ag NPs/PVA films

\section{2-2 Nonlinear properties of} AgNPs/PVA

Using Z-scan technique, the magnitude of nonlinear absorption and the sign and magnitude of nonlinear refraction can be determined simultaneously. When a high intensity laser beam propagates through a material, induced refractive index changes leads to selffocusing or defocusing of the laser 


\section{AL-Qadisiyah Journal of Pure Science Vol.23 No.3 Year 2018}

beam[8].Fig (1)The Z-scan experiment can be given as follows starting the scan from a distance far away from the focus (-z), the beam irradiance is low and negligible nonlinear refraction occurs leading to linear transmittance. As the sample is brought closer to the focus, the beam irradiance increases leading to self-lensing in the sample $[1,9]$

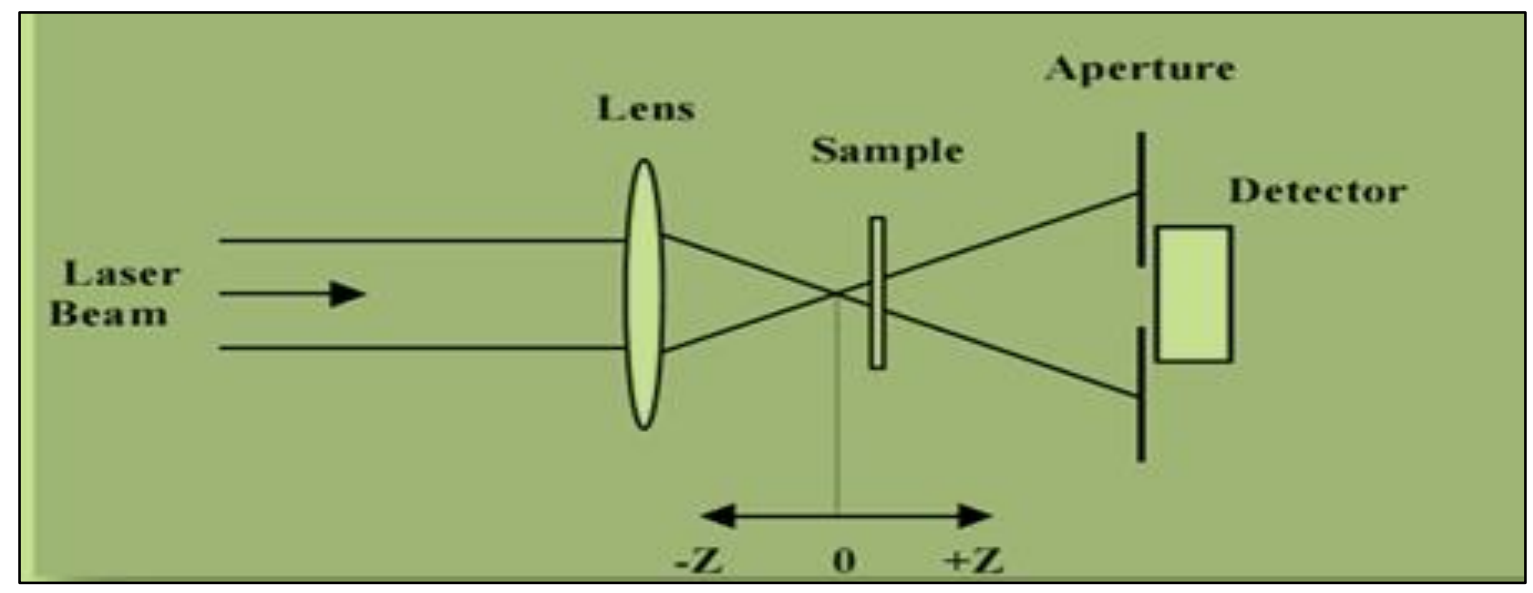

Figure (1): Z-Scan set up

The nonlinear refractive index is calculated from the peak to valley difference of the transmittance by the following formula [10].

$$
\mathrm{n}_{2}=\Delta \Phi_{\mathrm{o}} / \mathrm{I}_{\mathrm{o}} \mathrm{L}_{\mathrm{eff}} \mathrm{k} \ldots \text { ( (1) }
$$

Where $\Delta \Phi_{0}$ : - nonlinear phase shift, $\mathrm{k}=2 \pi / \lambda, \lambda:-$ is the wavelength of the beam.

$$
\Delta \Phi_{\mathrm{o}}=\Delta \mathrm{T} / 0.406 \quad \ldots
$$

$I_{0}$ is the intensity at the focal spot given by

$\mathrm{I}_{\mathrm{O}}=2 \mathrm{P}_{\text {peak }} / \pi \omega^{2}{ }_{\mathrm{o}} \ldots$
Where, $\omega_{0}$ : - the beam radius at the focal point,P: - the peak power of laser beam.

$$
\mathrm{L}_{\mathrm{eff}}=\left(1-\mathrm{e}^{-\alpha \mathrm{oL}}\right) / \alpha_{0} \ldots
$$

Where,L:the sample length, $\alpha 0$ : linear absorption coefficient.

The absorption of the material $(\alpha)$ is intensity dependent given by[11]:-

$$
\alpha=\alpha_{\mathrm{o}}+\beta \mathrm{I} \quad \ldots
$$

Where, $\beta$ : the nonlinear absorption coefficient related to the intensity, $\alpha_{0}$ : linear absorption coefficient. 


\section{3- RESULT AND DISCUSSION}

\section{3-1 X-ray diffraction of polymer} films

Fig(2) The X-ray diffraction peaks of polymer films doped with silver NPs occur at $2 \theta$ values of $\left(19.9^{\circ}, 38\right.$. $\left.34^{\circ}\right)$ and $\left(19.6^{\circ}, 44^{\circ}\right)$ in which it observed and compared with the standards powder diffraction card of (JCPDS), Ag file number (04-0783). The average particle size was measured by Debye-Sheerer equation $\mathrm{D}=(0.89 \lambda) /\left(\beta^{*} \operatorname{Cos}(\theta)\right) \quad \ldots \quad(6)$

Where $D$ is grin size, $\beta=F W H M, \theta$ is Diffraction angle [12]. The grain size of PVA doped Ag NPs thin film is shown inTable (1).

Table (1): Size of PVA \& Ag NPs/PVA as a function of laser pulses

\begin{tabular}{|l|l|l|l|l|}
\hline sample & $2 \theta^{\circ}$ & $\begin{array}{l}\text { Full width at half } \\
\text { maximum(FWHM) }\end{array}$ & NPs size(nm) & (h k l) \\
\hline PVA & 40.5 & $1.73 \mathrm{E}-03$ & 89.1 & 111 \\
\hline AgNPs/PVA & 38.34 & $5.28 \mathrm{E}-03$ & 26.01 & 111 \\
\hline
\end{tabular}

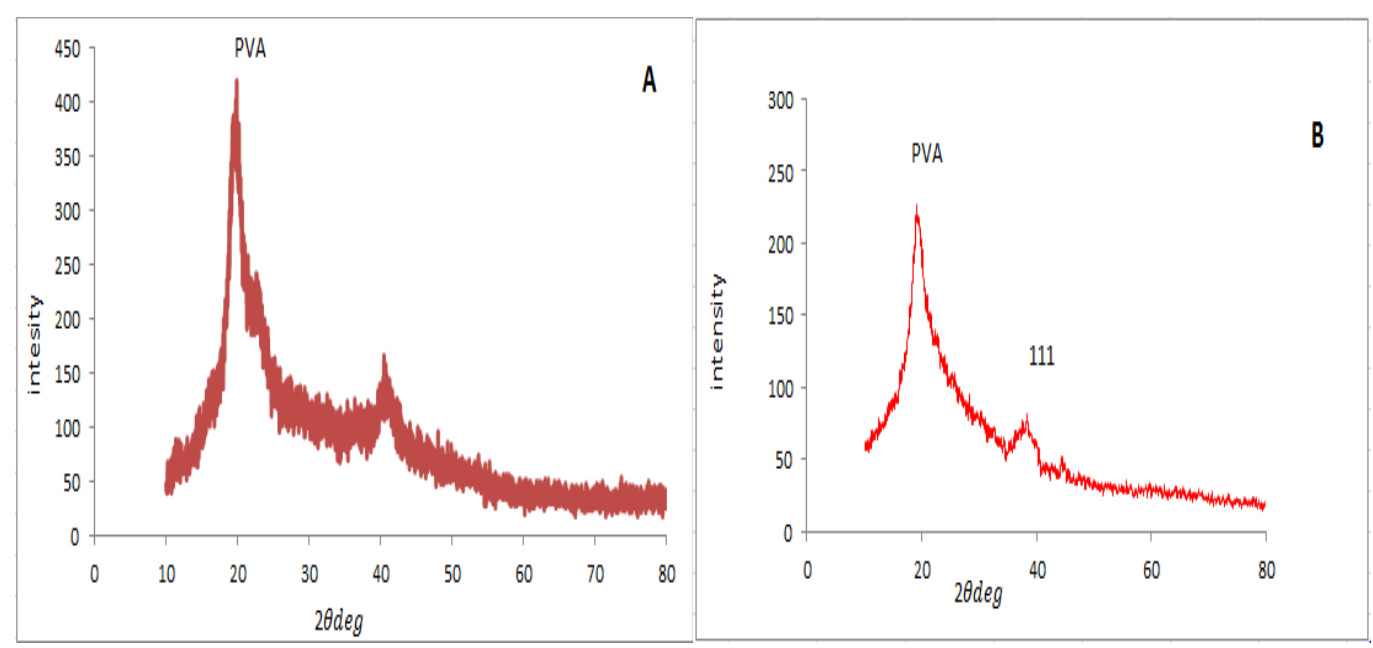

Figure (2) X-ray diffraction pattern (A) PVA (B) Ag NPs / PVA in ethanol at 100 pulses 


\section{AL-Qadisiyah Journal of Pure Science Vol.23 No.3 Year 2018}

3-2 nonlinear refractive and followed by avalley), and thenonlinear

\section{nonlinear absorption coefficient}

Fig $(3 a)(3 b)(3 c)$ The results show that the nonlinear refractive index negative (self-defocusing: that mean the peak absorption coefficient two photon absorption then the values of nonlinear refractive and nonlinear absorption coefficient indices are found as summarized in Table (2).

Table (2)Values of nonlinear parameters for prepared Ag NPs /PVA.

\begin{tabular}{|l|l|l|l|}
\hline pulses & $\Delta \Phi_{\mathrm{o}}(\mathrm{rad})$ & $\begin{array}{l}\mathrm{n}_{2} * 10^{-8} \\
\left(\mathrm{~cm}^{2} / \mathrm{W}\right)\end{array}$ & $\begin{array}{l}\beta^{*} 10^{-3} \\
(\mathrm{~cm} / \mathrm{W})\end{array}$ \\
\hline 100 & 0.78 & 1.02 & 2.49 \\
\hline 200 & 0.56 & 2.53 & 2.02 \\
\hline 300 & 0.14 & 3.98 & 1.63 \\
\hline
\end{tabular}
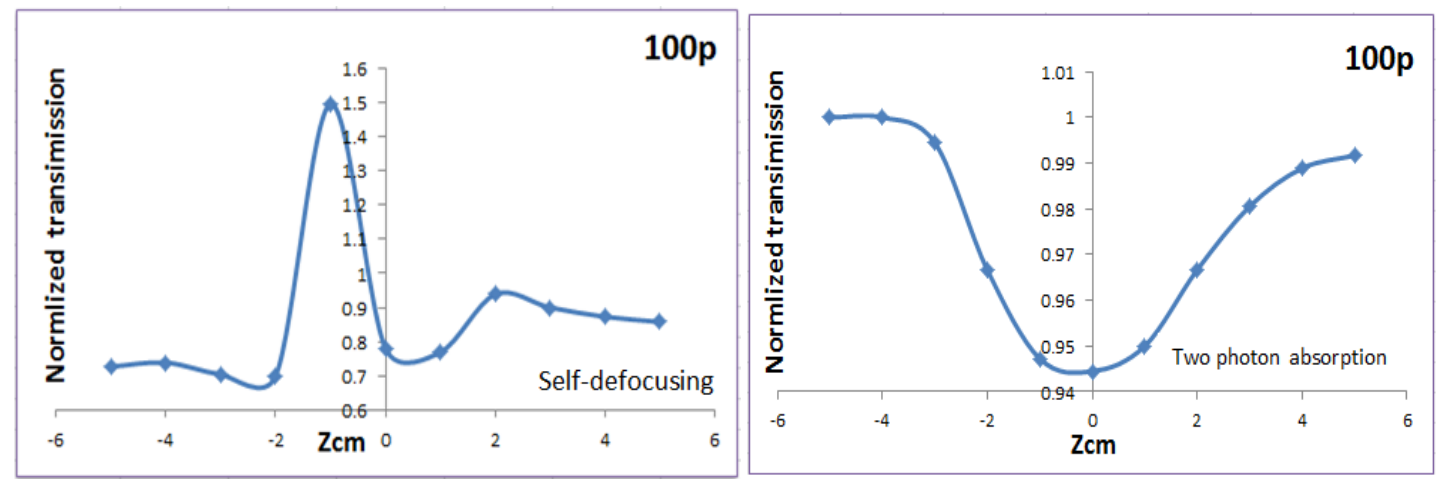

Figure (3a )Z-scan experimental data excitation Close aperture \&Open aperture curve, for AgNps /PVA
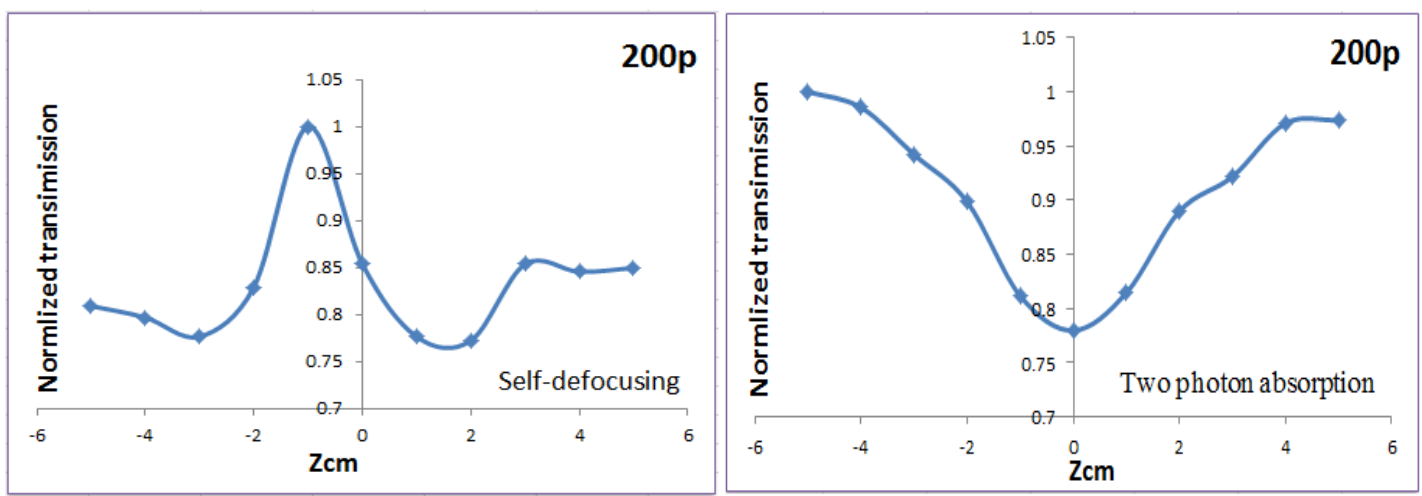


\section{AL-Qadisiyah Journal of Pure Science Vol.23 No.3 Year 2018}

Figure (3b) Z-scan experimental data excitation Close aperture \&Open aperture curve, for AgNps /PVA
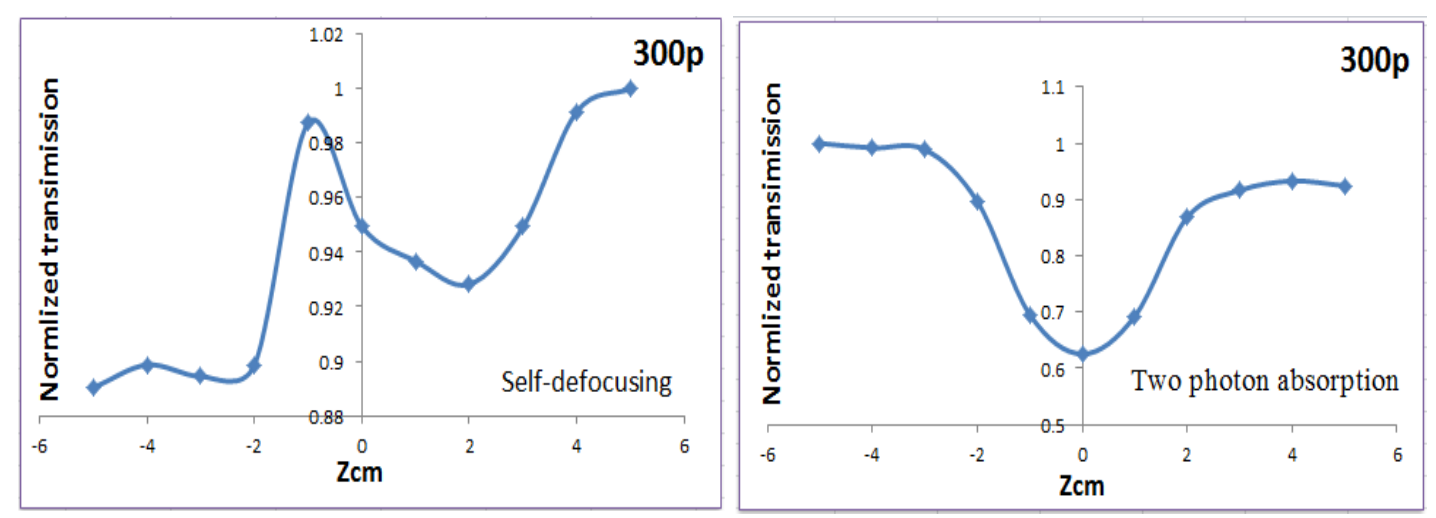

Fig (3c) Z-scan experimental data excitation Close aperture \&Open aperture curve, for AgNps /PVA

\section{4-Conclusion}

Nonlinear refraction of different composites containing AgNPs/PVA was studied employing, Z-scan technique, the nonlinear refractive index and nonlinear absorption were measured and the sign of nonlinear refractive index was found to be negative. The nonlinear refractive index increase from $-1.02 \times 10^{-8}$ $\mathrm{cm}^{2} \mathrm{~W}^{-1}$ to $3.98 \times 10^{-8} \mathrm{~cm}^{2} \mathrm{~W}^{-1}$. From the experimental conditions and theory fit results, we attribute the nonlinear absorption to TPA effect at $650 \mathrm{~nm}$.

\section{References}

[1]Amal F. Jaffar (The Effect of Polymer Blend on the Third Order
Nonlinearity of Oxazine Dye Doped Films by Using Z-Scan Techniques)Journal of Al-Nahrain University Vol.18 (3), pp.80-88, 2015. [2]NilanjalMisra, MounikaRapolu, S. VenugopalRao, LalitVarshney

Virendra Kumar (Nonlinear optical studies of inorganic nanoparticlespolymer nanocomposite coatings fabricated by electron beam curing) Optics \& Laser Technology 79,p. 2431, 2016.

[3]Raad. Sh. Alnaily, Manar .Lo .Dayekh (Practical Study on the Optical Limiter of KTP Crystal)AlQadisiyah journal for pure scienceVol. 23 No 2, 2018. 
[4]R A Ganeev, A I Ryasnyansky,Sh R Kamalov, MKKodirov and $\mathrm{T}$ Usmanov(2001)."Nonlinear

susceptibilities, absorption coefficients and refractive indices of colloidal metals"J. Phys. D: Appl. Phys. 34.pp.1602-1611.

[5]N. Faraji, W. Mahmood Mat Yunus, A. Kharazmi, E. Saion, M. Shahmiri, N. Tamchek, ,(2012)."Synthesis, characterization and nonlinear optical properties of silver/PVA nanocomposites" J. Europ. Opt. Soc. Rap. Public.7, pp.12040.

[6]XinChen, Jun Tao, Gang Zou, Wei Su, Qijin Zhang, Shiyong Liu, Pei Wang (2011)."Nonlinear optical properties of nanometer-size silver coated polydiacetylene composite vesicles and resulting LangmuirBlodgett films"ApplPhysA 102,pp.565-575.

[7]SamiS.Chiad ,SaadF.Oboudi , Khalid H. Abass ,Nadir F.Habubi(2012)"Characterization of Silver/ Poly (Vinyl Alcohol) (Ag/PVA) Filmsprepared by Casting Technique"Iraqi J. of Polymers Vol.16 , No.2, pp.10-18.
[8]EsmaeilShahriari, W. Mahmood Mat Yunus, KazemNaghavi and Elias Saion(2010)."The Optical Nonlinearity of $\mathrm{Au}$ and $\mathrm{Ag}$ Nanoparticle Prepared by the $\gamma$-Radiation Method"American J. of Engineering and Applied Sciences 3 (2): 260-264.

[9]Zahraa Sahib Shanon(2016)"Investigation on the Performance of Lithium Triborate (LBO) Crystal for Higher Harmonics Generation of LASERS", Thesis, University of Al-Qadisiayh Master of Science in Physics.

[10] R.Sh.Alnayli, Z. S.Shanon (2016)."Study of the nonlinear optical prpoerties of lithium triborate crystal by using z-scan technique" International Journal of Science and Research (IJSR)Vol, 5, Issue8.

[11] AdelehGranmayeh Rad, KhosroMadanipour, and Ata Koohian (2013)."AgNanoparticles Experimental Study of Sign Identification of Nonlinear Refractive Index by Moiré Deflectometry and Z-Scan Methods" ISRN Nanomaterials Volume 2013, Article ID 327575,pp.1- 6.

[12]AzhaarFarouqAbdlzhra, IssamAbdlkreemAbdllatief, and 


\section{AL-Qadisiyah Journal of Pure Science Vol.23 No.3 Year 2018}

EntesarEliwiLaabiAlabodi(2016)."Prep Polymer Blend (Poly vinyleacitet. aration and Characterization of Silver Pectin, poly Aniline"Ibn Al-Haitham Nanoparticles and Study Their effect Jour. for Pure \& Appl. Sci. Vol. 29 (3). on the Electrical Conductivity of the 